Revista Iberoamericana, Vol. LXXIII, Núm. 221, Octubre-Diciembre 2007, 905-917

\title{
ENTREVISTA CON RAFAEL COURTOISIE ${ }^{1}$
}

\author{
POR \\ Jesús Montoya JuÁREZ \\ Universidad de Granada
}

La obra de Rafael Courtoisie se extiende a lo largo de las últimas tres décadas. Inicialmente poeta, publicó desde fines de los setenta poemarios como Contrabando de auroras (1977), Tiro de gracia (1981), Orden de cosas (1986), Estado sólido (1996), Textura (1992) o Umbría (1999). Como narrador comenzó a publicar en los noventa sus libros de cuentos, entre los que cabe citar El mar interior (1990), El mar rojo (1991), El mar de la tranquilidad (1995), Cadáveres exquisitos (1995) o Tajos (2000), y novelas atípicas como Vida de perro (1998) o Caras extrañas (2001). Como él mismo señala, le gusta moverse entre géneros, saltando de la poesía al ensayo, del ensayo y la reflexión poética a lo narrativo, para vincular así sus facetas de poeta, narrador, académico y profesor de cine y literatura. Como pidiera Italo Calvino, la estética de Rafael apuesta por la levedad, por la ráfaga lúdica rociada de violencia, ternura y humor negro, por la asociación libre de ideas como modo de progresar y sugerir reflexiones que desembocan en preguntas abiertas, por el despliegue de la imaginación de este lado de las fronteras del realismo. A lo largo de nuestra conversación apela a Mandelbrot y su teoría de los fractales para hablar de su producción literaria, reconoce en su propia obra una intensa apropiación de las tecnologías de la información y lo mediático como condición y provocación en el proceso de lectura, y reflexiona sobre las transformaciones que posmodernidad, globalización y tecnología han provocado en la narrativa latinoamericana y sus narradores.

LA NECESIDAD DE NARRAR

Jesús Montoya (JM): Rafael, hasta ahora has sido más conocido como poeta, pero ahora estás siendo conocido por tu faceta como narrador. A partir de Vida de perro, aunque habías publicado varios volúmenes de cuentos con anterioridad, quizás es cuando internacionalmente te das a conocer...

Rafael Courtoisie (RC): Fundamentalmente desde Vida de perro, se ha dado una difusión internacional. Claro que el narrador ya existía y trabajaba a la par con el poeta desde mucho antes. Tengo tres libros de cuentos publicados en la llamada "trilogía de los

\footnotetext{
${ }^{1}$ El grueso del presente documento pertenece a una entrevista inédita que tuvo lugar en Montevideo, en enero de 2004. La versión definitiva que aquí presentamos se ha completado con algunas preguntas que nos han ido surgiendo mientras transcribíamos sus palabras.
} 
mares”: El mar interior, El mar de la tranquilidad y El mar rojo. Tres volúmenes que trataban de expresar heterodoxia y diversidad y que, una vez publicados, en conjunto se iluminaron entre sí de otro modo. Ése es un narrador que ya estaba trabajando pero es a partir de Vida de perro y de las novelas Caras extrañas y Tajos que hubo difusión internacional. Hasta ese momento mi repercusión en el Uruguay y en algunos círculos en España, entre otras cosas por el premio Loewe, había sido más como poeta que como narrador. Luego de la publicación de esas novelas encontré que mi narrativa entraba en consonancia con mucho de lo que se quería leer en ciudades como México, Bogotá o Caracas. La mayor difusión se da a partir de esas novelas, que creo son peculiares, no creo que sigan los paradigmas de novela del boom, sino que son relatos largos que tratan de dar cuenta de otro modo de zonas diversas de la realidad. Por ejemplo, Tajos, en donde el protagonista, una especie de psycho-killer ingenuo, un adolescente iracundo pero algo tonto, que entre otras cosas se propone asesinar al ratón Mickey, fue muy bienvenido y disfrutado por lectores de una megalópolis como Ciudad de México, y en otras grandes ciudades. A partir de allí sí hubo una “institucionalización”, se despertó un activo interés por mi obra en una amplia zona del periodismo cultural internacional y también desde el punto de vista de la academia. A partir de Vida de perro, en algunos seminarios de la universidad de Harvard sobre literatura hispanoamericana posmoderna, se incluye esa novela y el libro de poesía en prosa Estado sólido (1996) en el programa. En comparación, esos libros fueron decisivos frente al anterior proyecto de la trilogía de libros de cuentos que quedó en la penumbra, que tal vez fuera muy quiroguiano y a la vez carveriano.

JM: ¿Qué te ha llevado al hecho de narrar o, al menos, de distribuir tu narrativa? $¿$ Crees que ha llegado el momento de hacerlo o crees que hay que rescatar algo de la memoria de tu vida o de la memoria colectiva?

RC: Caras extrañas fue y sigue siendo un desafío, y sigue siéndolo aunque ya esté escrito. Por un lado hay elementos muy autobiográficos en la novela, pero por otro lado era consciente de que estaba tocando un tema tabú para la izquierda latinoamericana y para la uruguaya, y también para la derecha, si es que esas categorías siguen siendo operativas en términos tradicionales. Por decirlo de una manera menos pretenciosa, tal vez fuera un tema tabú para la sociedad uruguaya y en parte para la latinoamericana. La idea original era hacer una especie de crónica. Empecé a reunir mucho material, documentos, notas periodísticas, además de los elementos que tenía desde la época del asunto que es punto de partida de la obra: la toma por parte de los guerrilleros de una ciudad vecina a la capital del país. Tenía recuerdos concretos de ese hecho armado. Empecé a recopilar, a acumular materiales, crónicas de esa época, incluso testimonios, llegué a entrevistar a varias personas. Y me di cuenta que esa tarea podía ser interesante desde el punto de vista periodístico, desde el punto de vista de la crónica histórica o testimonial, pero no era relevante, no tenía sentido para mi proyecto de narración y construcción ficcional. Podía ser un libro que funcionara bien en términos de mercado pero que no tenía sentido autoral. Me di cuenta de que lo que quería referir era una historia privada, a la vez que tocaba un hecho público tabú, y que la única manera de contarla era dejar de lado ese cúmulo de informaciones y trabajar el tema desde la ficción, planteando un punto de vista humorístico, irónico, sarcástico, y a veces dramático. Estoy conforme en ese sentido. Creo que de otro modo hubiera sido una crónica más, tal vez, con suerte, simplemente correcta, pero que 
habría traicionado el proyecto literario que me proponía. La elección de un narrador niño, o de un adulto que rememora, brindaba varias posibilidades. Entre otras cosas, recuperar lo autobiográfico, pero además dar una mirada que saliera de toda pretensión de inscripción o filiación ideológica a priori. Esa decisión supone un riesgo en la América Latina de hoy, un riesgo de que a uno lo tachen, entre otras cosas, de desacralizador. Parecería que estos temas deberían ser sagrados, intocables. Para el niño que vivió parte de esa historia el tema no es sagrado, lo sagrado es la vivencia, la historia de las vidas privadas y los horrores que tuvieron que ver con eso. Creo que es una novela que trata de contar un hecho histórico desde lo que llamaban los franceses "historia de las mentalidades", o lo que se llamó aquí "historia de la sensibilidad”. ¿Qué pasa cuando una guerra, una revolución, un hecho armado, por heroico que parezca, cambia para siempre determinados parámetros de la vida cotidiana, de la vida personal, de la sensibilidad? Esa es un poco parte de la dimensión que traté de trabajar en Caras y en ese sentido estoy satisfecho.

JM: Utilizas como título una cita del tango “Sus ojos se cerraron”. ¿Qué valor le confieres al sintagma “caras extrañas”? ¿Es un concepto positivo, negativo o ciertamente ambiguo? ¿A qué o quién te refieres cuando un poco proféticamente hablas de "caras extrañas que vendrán”?

RC: La denominación “caras extrañas” no es a priori positiva ni negativa, y los que el gobierno tildaba en aquella época de sediciosos, los que aparecen en la ficción como Tapurí, corresponden en parte a los Tupamaros. La narración procura evitar mostrarlos como fenómeno negativo demonizado o como fenómeno positivo idealizado. No son los guerrilleros heroicos, pero tampoco dejan de serlo. Hay de todo. Por otro lado, además de los revolucionarios, la novela también se refiere a toda esa cohorte de casta militar que al fin se hizo con el poder y dio lugar, entre otras cosas, al terrorismo de Estado. De modo que las caras extrañas son todas; son tirios y troyanos. Por un lado, los que emprendieron acciones y despertaron un tigre dormido pensando que lo iban a dominar con unos pequeños golpes. Pero cuando el tigre se despertó se transformó en un aparato de desaparición de personas, en el terrorismo de Estado... Y también las caras extrañas son algunos agentes que aparecen allí en el libro no como testimonio sino como índice de que eso sucedió en la realidad, aparece un agente de la CIA...

JM: Aparece Robert Altman...

RC: Aparece, sí. Es al mismo tiempo un homenaje y una parodia del cine y los medios. Pero las caras extrañas son esas caras que con violencia irrumpen en ese "paraíso perdido" de la infancia. Cuando se expresa el vaticinio “ahora vendrán caras extrañas”, me parece que es como descubrir un hecho evidente e irreversible: ahora en la vida de cada uno van a seguir irrumpiendo, siempre, caras extrañas. Porque la modernidad no acabó con el fin de esas caras extrañas. Luego vienen, y vendrán, otras. De alguna manera el libro se sitúa en una posmodernidad, ya que no plantea una lógica o una razón de la modernidad, ve los sucesos terribles desde la óptica de la vida privada de un niño. Pero además ese niño toma conciencia de que esos sucesos, aquí o allá, pueden seguir sucediendo bajo diversas formas, en el continente americano o en el centro de Europa, aun de la Europa desarrollada, comunitaria y aparentemente civilizada. Las caras extrañas siguen irrumpiendo, creo que en ese sentido la historia no se acabó. Se cierran y se abren ciclos. Se acabó de pronto la pretensión de entender la historia como un todo a partir de un vector ideológico único, 
determinado. Pero la irrupción de caras extrañas prosigue en el tercer milenio, por ejemplo, hace poco aparecen "caras” que pretenden volar el tren Irún-Madrid. Estoy seguro de que en la vida de muchos niños que están hoy en el confort del primer mundo español se siente esa tremenda agresión, esa inseguridad. Eso está pasando también en Bagdad, y en todas partes. Pero la novela no trata del vaticinio de un profeta, sino de alguien que se hace adulto con temor y expectativa, y está esperando que lleguen otras Caras extrañas. Por eso la escena final de la novela tiene lugar junto a la fuente de los Cuatro Ríos en Roma. Uno de esos ríos es el Río de la Plata, otro es el Nilo... Lugares geográficos distantes ligados en la globalización... Esos cuatro ríos están mostrando cuatro flujos, cuatro puntos en el mundo donde pueden irrumpir esas caras extrañas. Sé que esto escapa a las ortodoxias, escapa a la bipolaridad buenos y malos. La utilización de la cita de Gardel: "Yo sé que ahora vendrán caras extrañas", creo que tiene que ver con la etapa de las incertidumbres y las heterodoxias. Ni el protagonista de Caras, ni probablemente el autor, plantean una polarización simple entre "buenos y malos”. En la izquierda y en la derecha hay buenos y malos, y corrupción, y vacilaciones. La verdad entera no está en ningún bando. En todo caso, la novela tampoco pretende explicitar "una" verdad, sino más bien brindar un ejercicio narrativo de apreciación de las diferencias.

JM: Hay en Caras extrañas la sugerencia continua de estar ante un universo irreal, cuando, sin embargo, se trata de algo terriblemente real. En tu opinión, ¿te consideras un narrador lúdico-fantástico, o más bien realista?

RC: Realismo-fantástico es una síntesis, es un oxímoron. Esa expresión fue empleada en la década del sesenta por muy buenos críticos latinoamericanos, entre quienes estaban los uruguayos Ángel Rama y Rodríguez Monegal, para mostrar la síntesis dialéctica entre esos dos opuestos aparentes. Y de ahí sale todo eso que se ha llamado realismo fantástico por un lado, y realismo mágico por otro. Creo que no hago realismo, en el sentido de "corriente literaria realista”, no me inscribo en eso. Tampoco hago algo puramente fantástico. Me gusta más ese matiz entre lo lúdico y lo fantástico. Advierto sí muchas veces que estoy hablando de la realidad a través del relato, pero no es realismo fantástico en el sentido que se le dio por los años sesenta. En todo caso se trata de una manera de relatar entre lo lúdico y lo fantástico. Tal vez la expresión "entre lo lúdico y fantástico”, que acabas de sugerir, parece mucho más cercana a lo que escribo, porque yo no suelo referir la realidad en forma mimética o figurativa, como sería propio del "realismo”. Sí suelo tratar de evocar la realidad y trabajar más las posibilidades connotativas que las denotativas. Trato de trabajar esas líneas de asociación connotativas a través de lo lúdico. Es más, en ese sentido, con independencia del género, creo más en la abducción, no tanto en la inducción ni en la deducción. No creo en un trabajo formal de tipo inductivo o deductivo, creo más en la aproximación de realidades, tanto en narrativa, como en poesía o ensayo, y que de alguna manera esa aproximación ilumine zonas de la realidad que estaban veladas. Es un procedimiento de abducción, de relámpago, si se quiere, de modo racional, pero racional intuitivo. Existe una razón poética que permite develar zonas de la realidad a través de la invención literaria Por una parte, hay una razón positivista, una razón “ordenada”, en la modernidad. En la llamada posmodernidad, que tal vez ya esté finalizando, en parte se da el advenimiento de una razón poética, que trabaja con formas espontáneas de conocimiento y con iluminaciones, en el sentido que daba a esta última palabra el adolescente Rimbaud. 
JM: Se te ha criticado en alguna ocasión el tratamiento que haces de la figura de la mujer en algunos relatos, como la mujer que obsesiona al protagonista de "Elisa, vida mía”; da la impresión en muchos casos de que sean retratos cinematográficos: prostitutas, adúlteras, malvadas, o a veces aparecen en tanto que aportan un componente sexual a la narración. ¿Estás de acuerdo?

RC: No es una narrativa misógina, para nada. Pero en todo caso sí hay marcas de género que aparecen allí como reflejos de la realidad. Tanto en Caras extrañas como en algunos cuentos de Cadáveres exquisitos aparece el hombre codicioso, ávido, inoportuno, desmedido, pusilánime, autoritario. Y aparece referido con cierta ironía y crítica. Y así como aparece el hombre ambicioso, pusilánime, aparece la mujer en algunos otros aspectos, positivos y negativos, y eventualmente en esos mismos. Esto no es para nada un proyecto de narrativa misógino, hay simplemente un rasgo descarnado, irónico de mi narrativa, que nunca trata de ser condescendiente, de escribir para "un público" o "nicho de mercado", de plantearse a priori llegar a una clase media que necesita caricias. No quiero hacer un ejercicio de lo políticamente correcto. Trato de pintar a mis personajes dentro del constructo de la ficción, exagerando algunas cosas, empleando un método análogo al de la caricatura. Pero eso ocurre igualmente en personajes masculinos y femeninos. No hay una visión única de la mujer, sino una variedad de visiones, una heterodoxia. En “Elisa, vida mía” hay muchas lecturas posibles. Allí hay una mujer ejecutiva, una mujer proactiva, audaz, que tiene la iniciativa, frente a un gordito abúlico que tal vez representa un modelo de marido de otra época, un paradigma de hombre que está en crisis. No creo que en "Elisa, vida mía” la mujer haga un papel de verdugo, sino que la mujer-personaje hace una suerte de emancipación, no sólo frente a ese paradigma de marido abúlico, de otra época, sino también respecto a su jefe dominante, a su amante. No creo que ese sea un modelo negativo de mujer.

JM: Quizás desde la perspectiva de los protagonistas y narradores masculinos se la pinta de este modo.

RC: Puede ser que aparezcan ciertos estereotipos de género que están en función de la narración, tanto en hombres como en mujeres. El hombre vengativo, ambicioso, el que se siente engañado. La mujer sometida. Pero no hay una crítica expresa de las ideologías subyacentes, sino que hay una mirada sarcástica, irónica, sobre la estupidez humana. Y la estupidez humana no es prerrogativa o territorio de un género. El machismo es a veces como la hemofilia, una enfermedad que pueden transmitir las mujeres y se manifiesta en los hombres, una mujer no puede ser hemofílica. La tragedia del machismo es como toda tragedia social: un problema que compete a todos los géneros, y a los dieciséis sexos que describieron ciertos sabios árabes de la antigüedad. No me preocupa lo políticamente correcto. He participado en muchas mesas redondas donde se plantea un código, una preceptiva con respecto al rescate que debería hacerse de lo femenino en una narrativa. Supongo que no debe haber “rescate” programático en la ficción. No hay por qué seguir preceptivas teóricas prefabricadas. Simplemente hay que construir una narrativa. Si esa narrativa no parece "correcta" respecto a lo "políticamente correcto", si eso no es condescendiente con determinadas formas de la sensibilidad contemporánea, es otro 
problema. De todos modos, creo que en parte de mi narrativa hay un papel importante de algunas mujeres, que aparecen como valerosas, heroicas, pero sobre todo que manifiestan una sensibilidad que en los personajes masculinos no suele manifestarse.

POSMODERNIDAD, MEDIOS Y PRODUCCIÓN LITERARIA

JM: Hay en determinado momento de ese libro una cita de Borges que dice que "el poema es la batalla misma”. ¿Cómo sostener que el poema es batalla, dentro del contexto posmoderno de las grandes editoriales y la mercantilización de la literatura?

RC: Justamente, es un contexto de contradicciones: el poema es la batalla pero al mismo tiempo la mercantilización de la literatura o más bien cierta literatura industrial puede hacer del texto un producto desangelado, inerte. En ese llamado contexto posmoderno hay, como en otros momentos, muchas paradojas. Algunas tienen que ver con una visión de la posmodernidad que es el vale todo, la coexistencia de los distintos proyectos que se cree pacífica. En esta condición posmoderna no hay una coexistencia pacífica de todas las concepciones de la realidad. Hay, sí, un grado considerable de información sobre esas distintas concepciones. Hablo, claro está, no solo de lo narrativo, de lo poético, hablo de concepciones de la vida y la organización social. La posmodernidad no se caracteriza porque coexistan pacíficamente los fundamentalismos, eso es obvio, sino porque hay una suerte de conciencia colectiva de que existen, tenemos información de que existen. Y a su vez entendemos que ninguno de esos fundamentalismos es preponderante. La posmodernidad tiene que ver con saber que existen grupos ultra feministas o el Lesbian Criticism de la academia norteamericana, al mismo tiempo que se sigue practicando la ablación del clítoris en el África subsahariana. La posmodernidad tiene que ver con el conocimiento colectivo de que esas dos expresiones ideológicas y de comportamiento están hoy en el mundo. Y son opuestas, y no conviven pacíficamente. Pero coexisten.

JM: ¿Consideras que la posmodernidad tiene que ver entonces con la lucidez?

RC: Tiene que ver más que con lucidez, con cierto grado de conciencia, de conocimiento, de esta aldea global, y en ese grado de conocimiento, no se reconoce uno de esos fundamentalismos como "totalmente" preponderante, como la "verdad". Se advierte una diversidad de verdades contradictorias. En esta condición posmoderna que, como dije, puede que ya está "finalizando", hay mucha información circulando sin calificación. En ese aspecto, la batalla citada del poema de Borges de la que hablábamos tiene que ver con la resolución en un texto de la pequeña verdad personal y de la procura de comunicabilidad de esa verdad puntual. Cuando allí se cita a Borges se plantea algo que tiene que ver con la posibilidad de comunicar y reproducir una realidad contradictoria, caótica. El poema, la narración, no tiene que ser la crónica racional, ordenada, de la batalla, sino que tiene que dar el espectáculo de la batalla, puede brindar "entretenimiento" al mismo tiempo que transmitir la crueldad de la batalla, sin obligarse necesariamente a una moraleja. En ese sentido Borges decía que el poema no debe ser la descripción de la batalla, sino la batalla misma. De algún modo, el constructo literario tiene que llevar el lenguaje a un límite, de modo que en cada lector se produzca, en términos estéticos, la intensidad de la batalla con su contradicción y su “entretenimiento” cruel. 
JM: Da la sensación de que eso es de algún modo también lo que hace la CNN: mostrar el espectáculo de la batalla y decir que esa es la batalla.

RC: Es diferente. La ventaja de los escritores es que en algunas cosas tenemos más independencia... El relato de las batallas de la CNN es también un constructo narrativo. De hecho hay, en términos audiovisuales, una gramática de imágenes que corresponde a la construcción de un relato. Y se puede determinar la estructura narrativa y se pueden determinar los “contenidos” y formas que se admiten en esa narración. Mientras la CNN relata una guerra, una cadena mexicana de noticias, Televisa, relata la misma guerra, pero con otros elementos. El relato de Televisa es entonces otra guerra. Es otro relato, otro constructo.

JM: Entonces, ¿crees que a la literatura le toca seguir produciendo relatos para competir con esos “relatos oficiales” u “oficialistas”, de ahí cuentos tuyos sobre las guerras del Golfo o los Balcanes?

RC: Tal vez la palabra no sea “competir”. Lo interesante es asegurar esa pluralidad de relatos. Cuando en el interior de Estados Unidos, ese relato de la guerra de origen mexicano, independiente, es censurado por muchos estados, creo se está privilegiando un relato frente a otros. Creo que la literatura en sí no tiene como misión dar todas las posibilidades de los hechos reales sino construir una realidad a partir de ciertos referentes. Me parece que en esta modernidad tardía o post lo que hago no es transmitir una verdad, no revelo determinados datos concretos que son, como diría Popper, "falsables", que son susceptibles de una verificación empírica, sino que creo un constructo donde se plantea una cierta sensibilidad. Yo no puedo decir "la verdad está en Caras extrañas”, o "la verdad está en mi cuento sobre la guerra del Golfo”, en todo caso hago un espectáculo, un entretenimiento que procura transmitir una sensibilidad. Creo que es una cuestión en la que se puede confrontar ese constructo con las referencias que cada lector individual tenga. Eco hablaba de la “cooperación interpretativa” del lector. Creo que es un concepto vigente.

JM: La unión del hijo de una guerrillera y la hija del torturador, el Coronel Saldías, la formación de una familia... ¿Crees que es más una metáfora sobre la posibilidad del encuentro o la constatación de que hoy todo está mezclado y no es posible reconocer las identidades?

RC: Ahí hay un deseo y una creencia. El deseo de que se superen los enfrentamientos, de que haya cierta compenetración, y la creencia de que es posible e improbable al mismo tiempo. Pero debe advertirse que hablamos de literatura, y eso está planteado en la obra casi en términos de "telenovela", de comedia, incluso en un planteo cursi de final feliz. Se ironiza sobre el happy ending. Es una provocación, tal vez un sarcasmo. Pero sí está el deseo de que sea posible. Pero ocurre que es posible si la sociedad restaña las heridas, si hay determinada sanación explícita, si se ponen en conocimiento público determinados crímenes de terrorismo de Estado. En esa medida sería posible. En la novela hay una búsqueda del recurso casi al kitsch o a lo cursi. Pero más allá el autor piensa que sí, que es posible. Esas escenas un poco cursis ponen en cuestión el universo de las ortodoxias, donde los buenos y los hijos de los buenos, y los amigos de los buenos, seguirán siendo buenos, y los malos y los hijos de los malos seguirán siendo malos. Esa visión del mundo me parece absurda, recurro al expediente de la parodia de la telenovela, pero por qué no 
va a suceder en la realidad. Todo se va mezclando. Incluso ese torturador, execrable, está contaminado, unido de forma muy fuerte a lo que él combatió, tiene un gato que se llama Che Guevara. En el nivel de lo doméstico ese gato que mea en las alfombras y tira los jarrones y lo importuna es un fantasma del pasado que está incidiendo en la vida de ese torturador. De manera menor y simbólica, claro. No es una gran "venganza” o vuelta de tuerca. El gato es un elemento doméstico que se proyecta como una parte, una sombra de su conciencia. La única manera de construir un futuro en nuestro país es superar por el camino de la verdad esas polarizaciones del pasado. No creo que pueda haber un idilio, no va a haber un idilio entre torturadores y torturados, pero no se va a llegar a un encuentro si antes no se plantea el tema de la verdad, de los desaparecidos. En ese punto ni la novela ni el autor confían en una solución de "final de comedia" o, en todo caso, de "final de tragedia”. La única solución posible es que la sociedad restañe sus heridas a través de un sinceramiento.

MEDios, VIOLENCIA Y REALIDAD VIRTUAL

JM: Hay en tu narrativa una fuerte poética de la violencia, un recurso a lo grotesco o a veces ridículo de la violencia y de la muerte, con tiros por todos lados y muertes narradas al uso de películas de acción o de dibujos animados. ¿Cuál es la pretensión? ¿Que se desdibuje la realidad que cuentas? ¿Parodiar la realidad y el modo en que nos llega? ¿Provocar que parezca un chiste a las claras? ¿Qué te seduce de esa llamada a lo grotesco por la vía de lo audiovisual? ¿Por qué hacer grotescamente divertidos los acontecimientos violentos que narras?

RC: No tiene que ver con tomar una realidad como un chiste. Tiene que ver con la formulación del discurso narrativo. Más allá de que pertenezca a la Generación del Silencio, de la Resistencia en Uruguay, con una serie de parámetros epocales que la enmarcaron, en este momento -estoy hablando del 2000 en adelante-siento que en buena parte de la narrativa latinoamericana -y en algunos casos hispanoamericana- existe la apropiación de determinados elementos del discurso narrativo audiovisual. No puedo escribir de la misma manera que Ciro Alegría escribe El mundo es ancho y ajeno, no puedo escribir de la misma manera en que García Márquez escribió El otoño del patriarca, ni que Vargas Llosa escribe La fiesta del Chivo. No es un afán de distanciarme de todos esos grandes nombres que respeto, o de alguien en realidad mágico y fantástico como es Juan Rulfo. No es la pretensión de cortar con los antepasados como programa de vanguardia, sino que me parece que con muchos de mis colegas narradores latinoamericanos hemos crecido en parte en el mundo audiovisual y en el digital. La violencia ficcionalizada la hemos recibido, prácticamente durante toda nuestra vida, mediatizada en términos de un timing, de un ritmo, de una vertiginosidad de la narración que la hace "espectacular" además de trágica. Algunos ejemplos de estas referencias audiovisuales: Pulp Fiction de Tarantino, aunque puede citarse un director mucho más solemne como Abel Ferrara....

JM: O un informativo...

RC: O un informativo, exactamente. Toda nuestra generación está impactada por esa presencia, o esa omnipresencia de los medios audiovisuales, y de una narración que es plano-contraplano, con cierta vertiginosidad, con cierta síntesis que ya de por sí es 
grotesca. La síntesis de veinte segundos de un flash de guerra es una caricatura de la guerra. Que mucha gente crea que eso es la guerra no quiere decir que lo sea. Se trata más bien de una caricatura de la guerra. Nosotros -y las generaciones que vienen después- estamos inevitablemente imbuidos de ese mundo de lo audiovisual. El gran desafío es no mimetizarse con ese mundo audiovisual, con esa manera de narrar. El libro nunca va a poder competir con el cine, o con la televisión, o con el video game. No tiene sentido esa competencia. Pero el libro sí puede alimentarse, como lo ha hecho desde que existe la escritura, de cualquier otro medio. McLuhan decía que no desaparece ningún medio. Creo que la literatura es una forma superior de realidad virtual. Uno puede llegar a sentir el estremecimiento de un estallido o de una caricia a través de un objeto abstracto que propone un código mediante un artefacto como el libro, sin necesidad de ser conectado, sin pilas. El discurso aparentemente lineal del libro provoca una representación en nuestra cabeza. Un libro es una terminal de realidad virtual. El narrador contemporáneo latinoamericano está profundamente imbuido de la cultura audiovisual y de masas, pero la vierte mediante la tecnología de la escritura, crea en otro sistema semiótico. El recurso al grotesco es una apropiación de la cultura audiovisual contemporánea (que a su vez se había apropiado de formas más primitivas del recurso en literatura). Pero sin olvidar que lo literario es, tautólogicamente, literario. Se trata de un sistema semiótico diferente del audiovisual. Una narración escrita puede estar llena de planos y contraplanos, diálogos vertiginosos y balas, pero después hay capítulos donde puede darse un tipo de creación estética y hasta de reflexión incomunicables por los medios audiovisuales. De la conjunción de lo intrínsecamente literario y de la digestión de esa omnipresencia de lo audiovisual y lo informático provendría buena parte de esta nueva narrativa. Estoy pensando en un narrador boliviano, Edmundo Paz Soldán, en su novela Sueños digitales. Creo que la presencia de lo digital y la manipulación de imágenes le da la oportunidad de reelaborar la "novela del dictador" sin ser un epígono de El otoño del patriarca ni de Tirano Banderas. Lo cuenta como se puede contar en la posmodernidad. El recurso al grotesco y a la violencia es en parte una marca generacional de las nuevas formas narrativas latinoamericanas, o hispanoamericanas. Insisto, es un desafío frente a la narración de esa violencia que hace lo audiovisual, no una mimetización. No estamos escribiendo libretos televisivos sino, en todo caso, haciendo recordar al lector que existe todo ese universo y jugando con los reflejos condicionados del lector ante ese universo, con lo subyacente...

JM: La muerte aparece en tus relatos con frecuencia como epíteto que resuelve cada escena, como ocurre en algunos de tus cuentos, en Tajos, o más insistentemente en Caras extrañas, donde los guerrilleros o los milicos acaban con todos los protagonistas y los proyectos que puedan plantearse... Cuando el narrador de Caras dice que "no existe la revolución, existen los hijos”, cuando haces aparecer la muerte de esa manera sistemática y a veces obsesiva, ¿a qué está apostando el escritor? ¿Estás queriendo decir que ninguna de esas ideas merece la pena? ¿Es una burla, un decir que ninguno de estos relatos utópicos tiene sentido? ¿Qué quieres rescatar y qué quieres destruir en tus lectores?

RC: Creo que de pronto haría trampas al solitario si ahora te comunico una moraleja, un mensaje. Una de las cosas que el libro pretende es crear un entretenimiento y que el mensaje lo construya el lector. Tengo una opinión como autor, pero quizás “mancillara” la lectura si ahora intentara revelar mesiánicamente un "mensaje”. En todo caso, tal vez 
exista la búsqueda de un planteo humanista "por el absurdo". Creo que tampoco es tan nuevo lo que plantea el libro con esa omnipresencia de la muerte. Es antiguo. Salvando las enormes distancias cito el famoso soneto de Quevedo: "Miré los muros de la patria mía, si un tiempo fuertes, ya desmoronados”, que termina diciendo: “y no hallé cosa en que poner los ojos que no fuese recuerdo de la muerte”. Tal como Quevedo ve en su tiempo la destrucción de "los muros de la patria mía”, así la hemos percibido en épocas oscuras algunos habitantes de Latinoamérica, sin hallar cosa en que poner los ojos que no fuese recuerdo de la muerte. Pero si eso ya lo formuló en un exacto soneto un poeta como Quevedo, no creo que sea nuevo, en todo caso los planteos temáticos se resignifican. Reitero que no puedo dar un mensaje o una moraleja explícita, traicionaría al libro. Creo que además existen varias posibilidades. Quiero creer que el texto es polisémico. Sería terrible que mi libro fuera una especie de fábula moral. No lo quiso ser. En todo caso, el lector tiene la libertad de ejercer, a partir del libro, su propia construcción de significado...

LO MEDIÁTICO EN LA NARRATIVA LATINOAMERICANA

JM: Aunque pueda sonar pretencioso responder, la gramática audiovisual, las irrupciones lúdicas en la realidad, el humor... ¿qué crees que un modo de narrar como el que propones puede estar aportando en la narrativa latinoamericana actual? ¿A qué narradores actuales te sientes cercano?

RC: Contestar en términos “literales” sería de una pedantería extrema, y la pedantería es también otra forma de inconsciencia o ignorancia. Lo que creo es que mi proyecto de creación es consciente, y no pasa por una formulación exclusivamente narrativa. Creo que lo que trabajo en poesía, narrativa y eventualmente en ensayo se relaciona entre sí de modo tal que no se trata de actividades paralelas y de distinto orden, sino que están dentro de un mismo orden, del mismo proyecto de creación. No sé si eso es original, pero sí me doy cuenta que descubro posibilidades y que logro crear cosas que de otro modo no haría. Escribí un cuento muy breve que se llama “Persistencia del débil”, que está incluido en uno de mis libros de relatos, El mar rojo. Ese mismo texto puede ser leído como texto poético, se puede leer como cuento y creo que tiene mucho de ensayo, de exploración reflexiva a través de una anécdota. No sé si eso resulta un aporte importante, pero es algo que entiendo como una peculiaridad en mi proyecto de creación. Incluso no me interesa mucho hacer o seguir taxonomías y distinguir entre géneros, lo que me interesa es trabajar. Esto tal vez vaya a contracorriente de la simplificadora y reduccionista producción "industrial” de literatura y de ciertos aparatos críticos. Caras extrañas es una novela pero que creo que tiene contenidos ensayísticos o poéticos, y no creo que sea una mezcla sino que es en todo caso un proyecto sinérgico y sincrético. Por otro lado, también sería pretencioso plantear qué narradores “están” en esta misma línea. En todo caso puedo plantear mi ascendencia. Me siento cercano a ciertos narradores concretos. Algunos de un pasado: he hablado de Borges, pero podría hablar de Cortázar. Cortázar ha muerto, pero está vivo en sus textos, vigente, es un referente cultural que me consta leen los muchachos de dieciocho o veintipocos años. Lo siento muy vigente, siento que es una presencia viva para mí. Por otro lado hay otros narradores como Piglia o Saer. Piglia en especial porque es capaz de trabajar estructuras narrativas aparentemente muy novedosas y experimentales, con todo el riesgo 
que eso significa, como por ejemplo en La ciudad ausente o en Respiración artificial, pero al mismo tiempo es capaz de convertir una crónica violenta de la realidad en una obra de creación propia, intransferible, como es Plata quemada, que en su primera versión se llamó "Por amor al arte".

JM: ¿Qué me dices de César Aira?

RC: Siento una gran admiración y en ocasiones cierta cercanía con algunas de las muchísimas obras que ha publicado Aira -tiene algo así como cincuenta novelas publicadas, es una máquina de producción. César trabaja la estructura con sesgo irónico. La gramática escénica en parte de su narrativa se corresponde con la gramática de imagen del cómic, del dibujo animado. También los personajes y el trazo de la peripecia. Usa estereotipos del cartoon: el genio maligno, el tonto adlátere del genio, en tono paródico también. Hay en Aira una línea de trabajo con lo lúdico-fantástico, para reiterar esa etiqueta, que me hace sentir próximo. Sobre todo estimo la ruptura con una solemnidad que viene de esa novela totalizadora de los sesenta, de lo que se llamó el boom. Una ruptura lúdica, zumbona, no la ruptura programática de una generación de vanguardia que quiere hacer una toma de poder en los aparatos de legitimación literaria, sino la ruptura en los hechos textuales. Esto se puede apreciar en novelas como Cómo me hice monja o El congreso de literatura. En otro sentido, quiero mencionar a otro autor como Roberto Bolaño. En sus cuentos o en Los detectives salvajes, una novela desmesurada, de una enorme extensión física, pero no una novela "totalizadora” como las del sesenta o algunas del setenta. Creo que está escrita desde un registro de sensibilidad concreto, personal y no "pretencioso", aunque provocativo. También me interesa de Bolaño la ruptura con lo políticamente correcto: al respecto puedo citar cuentos como los de Putas asesinas. Hoy mencionabas el tema de las mujeres en mi narrativa. Pues bien, creo que Bolaño también trabaja con ciertos estereotipos de la realidad, con marcas de género, aunque eso no necesariamente lo hace misógino. En Aira, en Bolaño y en otros está el humor, está presente lo lúdico, las ganas de disfrutar con lo que se está haciendo y las ganas de hacer disfrutar al lector sin compromisos a priori con lo "correcto" en el sentido de preceptiva moral.

JM: ¿Crees que hay en ese sentido un gusto por lo excesivo en la presentación fantástica de la realidad por parte de los narradores latinoamericanos que no se da con tanta frescura en la narrativa que se está escribiendo en España, por ejemplo?

RC: Hay de todo a los lados del océano. En alguna narrativa contemporánea española hay ciertos bretes de solemnidad. Tal vez frente a esa zona una parte de la nueva narrativa hispanoamericana apueste por romper la solemnidad a partir del exceso. Hay un juego de palabras: en parte de la literatura española hay un exceso de solemnidad, y en parte de lo latinoamericano, hay un recurso al exceso para romper la solemnidad. Ahora, habría que hilar un poco más fino en esto, porque acabo de leer Lo mejor que le puede pasar a un cruasán, y en esa obra no creo que haya solemnidad. Creo que es una obra que va a contracorriente de parte de lo que he leído de literatura peninsular, creo que comparte muchos de los puntos que hemos visto como comunes a los narradores latinoamericanos. Tiene velocidad, vértigo de tipo cinematográfico, pero sigue siendo intrínsecamente literario a nivel discursivo. Y está el humor. El humor está presente de una manera tan fuerte en la novela, que convierte al posible referente “real” en algo fantástico. Así como 
Felisberto Hernández, el narrador uruguayo, construye con su mirada el espacio de lo fantástico a partir de un referente cotidiano, el humor en Tusell crea un efecto análogo. Estaba ahora pensando en otros autores españoles que trabajan también con esa impronta de lo audiovisual, uno es Ray Loriga, otro Benjamín Prado, pero creo que allí no se da una abierta apelación al humor. En Latinoamérica está el caso de Fernando Vallejo. La apelación a la violencia que hace en su obra y en particular en La virgen de los sicarios, resulta a la postre también irónica. Hay una retórica del exceso vertida en aparente ritmo de vértigo cinematográfico. Pero si uno conoce la realidad colombiana, lo de Vallejo puede leerse como una crónica "mesurada" de la realidad. Hemos hablado de esto con algunos autores latinoamericanos. Se trata de una retórica diferente a la que narra o refiere la violencia revolucionaria o contrarrevolucionaria y represora. En esta narrativa más reciente aparece la violencia individual, urbana, la cultura de la droga, la cultura del malestar. Quien conoce ciudades latinoamericanas como Bogotá, San Pablo, México, puede descubrir que hay más violencia en la realidad que en la literatura. Que en todo caso la literatura ha procurado violentar códigos para expresar parte de esa otra violencia “real”.

\section{TECNOLOGÍA Y LITERATURA LATINOAMERICANA}

JM: Globalización y penetración de la tecnología aparecen, pienso, como una constante en tu producción narrativa y poética. En Vida de perro por ejemplo me parecen muy recurrentes las metáforas maquínicas y tecnológicas que empleas para describir y pensar a partir de realidades muchas veces sentimentales. ¿Qué te seduce de las máquinas de nuestro tiempo o de las tecnologías de la comunicación?

RC: Entre otras cosas, “apropiarse” de zonas del discurso tecnológico, científico o comunicacional otorga una posibilidad de expresión diferente, por momentos más “efectiva”, puesto que funda y permite renovar sistemas metafóricos. Por otra parte el recurso permite cuestionar, o al menos problematizar, el divorcio tradicional entre humanismo y disciplinas científicas. Toda construcción de saber es un fenómeno humano. Y la construcción de discurso está en el centro de ese fenómeno.

JM: Antes citabas a McLuhan y el solapamiento de los diferentes medios. ¿Cómo piensas que ha afectado a la literatura su relación con las nuevas tecnologías y la penetración de los mass media?

RC: Le plantea varios desafíos. Entre ellos la disyunción ya señalada entre una simple actitud mimética (condenada al fracaso expresivo) o una reformulación con conocimiento consciente de su propio e intransferible sistema semiótico, de sus posibilidades. Por supuesto que se dan por otra parte los “temas de mercado" en la era de los mass media: libros que se escriben mal o rematadamente mal, libros que se escriben y editan para ser filmados y resultan malas novelas y malos remedos de guiones... mala literatura. El efecto collage, la apelación a un ritmo diferente y a una estructura narrativa vertiginosa no deben ser confundidos con la mélange, con la mera mezcla confusa. Son riesgos que plantea la escritura creativa en este comienzo de milenio.

JM: Algunos críticos han hablado de una tendencia centrífuga en la narrativa latinoamericana más joven, tanto en sus motivos como por representar espacios y problemas ajenos a realidades latinoamericanas. Otros han interpretado la seducción por 
lo mediático y lo masivo como el fin de la tradición narrativa latinoamericana en la medida en que habría perdido su distancia irónica y sería, supuestamente, fagocitada por el mercado transnacional que marcan las grandes editoriales euro-norteamericanas y la academia, fundamentalmente estadounidense. ¿Qué piensas tú de todo esto? ¿Crees que estos planteamientos son excesivamente apocalípticos o reduccionistas respecto de lo que es o ha sido la narrativa de Latinoamérica o crees por el contrario que puedan ser en cierta medida acertados?

RC: El título de Umberto Eco, “Apocalípticos e integrados”, me sigue pareciendo a este respecto provocador y útil: personalmente creo que en ocasiones se debe ser un apocalíptico optimista (valga el oxímoron) y lúcido, y en otras ocasiones un integrado crítico. La tendencia centrífuga que mencionas puede tener otra lectura: en parte se han relativizado los “centros” en términos geopolíticos de legitimación y referencia estética. Muchos márgenes se vuelven centros. La imposición de que la literatura latinoamericana deba continuar construyendo y brindando la "postal exótica” del trópico, con guacamayas y palmas exclusivamente, me parece de inspiración estrecha. Hay en esa imposición una búsqueda de confirmación del lugar del "subalterno". Los escritores latinoamericanos de hoy pueden hablar de lo que les plazca. La división entre "temas universales” o centrales y "temas locales", pintorescos, es artificiosa para un continente que posee algunas de las más grandes y problemáticas ciudades del mundo. Pienso que coexisten maneras válidas de lo universal y de lo local, y que lo local deviene universal y viceversa. $\mathrm{O}$ en ocasiones se crea lo "glocal”. Quizá sea pertinente citar por ejemplo dos corrientes diversas de narración en el panorama mexicano actual: por un lado los llamados "bárbaros del norte”, creadores de una narrativa muy poderosa que se nutre de la compleja problemática fronteriza y la torna universal, por otro lado la llamada "generación del crack", de apariencia más "global” o universal, pero que es tan latinoamericana como la otra, aunque los escenarios en ocasiones sean europeos. En referencia al pasado: Borges no es un escritor europeo. Es, a su manera, latinoamericanísimo en sus dos vertientes: su poesía y su narrativa tributarias de una no escrita "enciclopedia criolla” y la poesía y narrativa que corresponden a la Enciclopedia Británica. Borges es tan latinoamericano como García Márquez. Ambos son, en términos figurativos, a su manera, mestizos. 
